Sônia Soares ${ }^{1}$

\title{
ANÁLISE DO DIREITO HUMANO À ALIMENTAÇÃO ADEQUADA: UM DIREITO SOCIAL E POLÍTICO
}

Analysis of the right to adequate food: A social and political human right

${ }^{1}$ Universidade Federal do Rio Grande do Norte. Natal/RN, Brasil.

Correspondência: soniafilos@yahoo.com

Recebido: 03/09/2017. Revisado: 27/09/2018. Nova revisão: 18/12/2017. Aprovado: 09/01/2018. 


\section{RESUMO}

Neste artigo, analisa-se a distinção aceita pela Organização das Nações Unidas entre os direitos humanos estabelecidos na Declaração Universal dos Direitos Humanos, da qual resultaram dois pactos internacionais de direitos humanos. Assim sendo, o Pacto Internacional de Direitos Econômicos, Sociais e Culturais reconhece o direito humano à alimentação adequada como um direito social e não como um direito político, assumindo que sua realização deve se dar de modo progressivo e não imediato. Para verificar a pertinência de superar a tese da progressividade, resgatam-se inicialmente suas origens, a partir do exame de documentos das Nações Unidas; em seguida, com base em referências que denunciam a hierarquização dos direitos, faz-se uma análise crítica das obrigações dos Estados indicadas pela Organização das Nações Unidas para a garantia do direito humano à alimentação adequada. Para expor a dificuldade em conciliar a indivisibilidade dos direitos humanos, reafirmada na Conferência Internacional de Direitos Humanos (Teerã, 1968), com a progressividade defendida no Pacto Internacional de Direitos Econômicos, Sociais e Culturais para a realização do direito à alimentação, apresenta-se como exemplo o caso concreto do perfil nutricional da população brasileira. Reconhece-se o múltiplo aspecto do direito humano à alimentação adequada, seja como direito social, seja como direito político; que não é possível tolerar a realização do direito de estar livre da fome sem respeitar o direito de acesso a alimentos adequados; e que é preciso reivindicar sua imediata efetivação. $O$ fundamento para esta defesa não pode ser outro senão aquele afirmado na Declaração Universal dos Direitos Humanos: a dignidade da pessoa humana, princípio este que não admite gradação nem pode ser dividido.

\section{Palavras-Chave}

Direito à Alimentação; Direitos Humanos; Pessoalidade.

\section{ABSTRACT}

This article analyzes the United Nations accepted distinction of human rights proclaimed by the Universal Declaration of Human Rights, which resulted in two international covenants on human rights. The International Covenant on Economic, Social and Cultural Rights recognizes the right to adequate food as a social and not a political right, assuming that it must occur progressively rather than immediately. In order to verify the pertinence of overcoming the thesis of progressiveness we initially rescue its origins, starting from the analysis of United Nations documents; we proceed with a critical analysis of State obligations, under the United Nations, to guarantee the right to adequate food, based on references that denounce the hierarchization of rights. To expose the difficulty in reconciling human rights indivisibility, reinforced at the International Conference of Human Rights (Teheran 1968), with International Covenant on Economic, Social and Cultural Rights advocating for the progressiveness for the fulfillment of the right to adequate food, we took as example the concrete case of the Brazilian population nutritional profile. The double aspect of the right to adequate food is recognized, both as a social right and a political right; the right to be free from hunger depends on respecting the right of access to adequate food; and it is necessary to claim its immediate fulfillment. The foundation for this defense can be no other than human dignity affirmed in Universal Declaration of Human Rights, a principle that admits no gradation and cannot be divided.

\section{Keywords}

Human Rights; Personhood; Right to Food. 


\section{Introdução}

A alimentação adequada foi considerada um direito humano ${ }^{1}$ pelo Pacto Internacional de Direitos Econômicos, Sociais e Culturais ${ }^{2}$ (PIDESC), adotado pela Organização das Nações Unidas (ONU), juntamente com o Pacto Internacional de Direitos Civis e Políticos ${ }^{3}$ (PIDCP), em 1966. ${ }^{4}$. Cabia aos pactos conferir obrigatoriedade aos direitos e liberdades afirmados na Declaração Universal de Direitos Humanos $^{5}$ (DUDH), na qual se fazia uma referência apenas indireta ao direito à alimentação, como parte do direito à vida.

A DUDH não tem poder vinculante, mas o pacto, enquanto tratado ou convenção internacional, vincula as pessoas (titulares de direitos) aos Estados (titulares de obrigações $)^{6}$. Uma vez firmados os pactos, os Estados se comprometem a tomar medidas para sua efetivação, o que inclui tanto a adequação das leis domésticas como a assinatura de protocolos que representem a possibilidade de denúncia e investigação de violação de direitos?

Uma importante consequência da distinção entre direitos sociais e direitos políticos que se expressa nos dois pactos foi a proposta de realização progressiva do direito humano à alimentação adequada, considerado um direito social e não um direito político. Este artigo busca construir uma crítica à tese da progressividade no sentido de contribuir para uma melhor compreensão das dimensões do direito humano à alimentação adequada, tomando como exemplo $\mathrm{o}$ atual perfil nutricional brasileiro. Para tanto, investiga as origens dessa tese no contexto da elaboração da DUDH, mediante exame dos documentos oficiais; elabora uma análise crítica das obrigações dos Estados indicadas pela ONU para a garantia do direito humano à alimentação adequada, ancorado em referências que denunciam a hierarquização dos direitos; e aponta elementos de incompatibilidade entre a progressividade e o princípio da indivisibilidade dos direitos humanos que possam justificar a exigibilidade da realização imediata do direito humano à alimentação adequada.

\section{0 direito humano à alimentação adequada: as origens da progressividade}

Em 1950, dando seguimento à elaboração da DUDH, foi apresentada à Assembleia Geral da ONU a proposta de um pacto, referente às liberdades civis e políticas. Tal proposta foi rejeitada porque a Assembleia ${ }^{8}$ entendeu que "o ser humano privado dos direitos econômicos, sociais e culturais não representa a pessoa humana que a Declaração Universal considera como ideal de ser humano

\footnotetext{
${ }^{8}$ UNITED NATIONS - UN. General Assembly - $5^{\text {th }}$ Session. Resolution 421 (V). Draft International Covenant on Humans Rights and Measurs of Implementation: Future Work of the Commission on Human Rights. p. 43. Disponivel em <https://documents-dds-ny.un.org/doc/RESOLUTION/GEN/NRO/060/19/IMG/NR006019. pdf?OpenElement>. Acesso em: 12 jan. 2017.
} 
livre" e solicitou à Comissão de Direitos Humanos do Conselho Econômico e Social das Nações Unidas (ECOSOC) incluir expressamente na proposta apresentada "os direitos econômicos, sociais e culturais de modo a relacioná-los com as liberdades civis e políticas"

Se bem observarmos, tanto os direitos e garantias individuais (os chamados direitos civis e políticos) como os direitos sociais já faziam parte do conjunto de direitos apresentados no corpo da $\mathrm{DUDH}^{10}$. No entanto, como não houve consenso absoluto ${ }^{11}$ na afirmação dos direitos humanos declarados pela ONU, chegou-se mesmo a pensar que nem era necessário um pacto para os direitos sociais, uma vez que estes poderiam ser promovidos apenas progressivamente ${ }^{12}$. Os defensores da separação em duas categorias de direitos acreditavam que os direitos incorporados ao Pidesc - nos quais se inclui o DHAA -, por constituírem direitos coletivos que dependeriam das condições do Estado para garanti-los, não seriam de obrigação vinculante e não teriam efeito jurídico direto; sua aplicação não seria imediata, mas progressiva. Os direitos reconhecidos no PIDCP, por outro lado, seriam de caráter absoluto, isto é, aplicáveis de imediato, por serem individuais ${ }^{13}$.

Pode-se dizer que a nova organização do mundo pós-Guerra, dividido entre Estados socialistas (defensores dos direitos econômicos e sociais) e Estados capitalistas (que defendiam os direitos civis e políticos) ${ }^{14}$, levou, quase duas décadas após a apresentação daquela proposta inicial de pacto, à elaboração e adoção de dois pactos - já que grande parte dos países socialistas não assinou o Pidcp, e muitos países capitalistas não assinaram o Pidesc, entre eles os Estados Unidos ${ }^{15}$, que ainda hoje não reconhecem a alimentação como direito ${ }^{16}$, embora denunciem

9ld. Ibid., p. 43.

${ }^{10}$ Os direitos civis e políticos são apresentados nos artigos $1^{\circ}$ a 21; do artigo 22 ao 28 apresentam-se os direitos sociais, econômicos e culturais.

${ }^{11}$ Dentre as 64 nações, abstiveram-se de votar a favor da DUDH: União Soviética, Ucrânia e Rússia Branca (Bielorússia), Tchecoslováquia, Polônia, lugoslávia, Arábia Saudita e África do Sul.

${ }^{12}$ UNITED NATIONS - UN. Draft International Covenants on Human Rights: Annotation. Prepared by the Secretary-General. Chapter II (12). Disponível em: <http://repository.un.org/handle/11176/302618>. Acesso em: 20 jan. 2017.

${ }^{13}$ UNITED NATIONS - UN. Draft International Covenants on Human Rights: Annotation. op. cit.

${ }^{14}$ Mesma distinção se verificava entre as chamadas declarações modernas (norte-americana, de 1776, e francesa, de 1789) e a declaração do povo trabalhador e explorado da antiga União das Repúblicas Socialistas Soviéticas (URSS), de 1817.

${ }^{15} \mathrm{Em}$ discurso na Sorbonne, a primeira-dama americana Eleonor Roosevelt explicou que os Estados Unidos se distinguem da URSS na forma de considerar os direitos econômicos, sociais e culturais porque entendem que certos direitos jamais deveriam ser concedidos pelo governo, e sim mantidos nas mãos do povo. FACING HISTORY AND OURSELVES. Social and Economic Rights: Eleanor's Speech at the Sorbonne. Disponível em: <https://www.facinghistory.org/universal-declaration-human-rights/social-and-economicrights-eleanors-speech-sorbonne>. Acesso em: 31 ago. 2018.

${ }^{16}$ Algumas cidades norte-americanas estabelecem multa de 500 dólares ou 60 dias de prisão para quem fornecer comida a moradores de rua. NATIONALHOMELESS.ORG. New report: the criminalization of foodsharing practices. Disponível em: <http://nationalhomeless.org/new-report-criminalization-food-sharingpractices>. Acesso em: 31 ago. 2018. 
amplamente a violação de direitos humanos quando se trata das liberdades civis e políticas em outros países.

Historicamente, no âmbito das gerações ${ }^{17}$ de direitos, os direitos civis e políticos constituem a primeira geração e traduzem o ideal de liberdade do súdito - transformado em cidadão - perante o governante, que se expressa no direito de participar do poder, agora limitado; tais direitos surgem das lutas contra o Estado absolutista, cujo poder não tinha limites. Já os direitos econômicos, sociais e culturais, considerados de segunda geração, nascem das lutas por melhores condições de vida e trabalho, em uma época de capitalismo nascente, e se articulam em torno do ideal de igualdade ${ }^{18}$, associado à justiça social que vai dar origem ao Estado de bem-estar social. No dizer de Bobbio ${ }^{19}$, são também direitos de liberdade, só que "por meio do Estado"; enquanto os primeiros têm uma base individual e limitam o poder do Estado sobre o indivíduo, implicando o dever de abstenção, os segundos têm uma base coletiva e exigem a intervenção do Estado para sua garantia, ou seja,

${ }^{17}$ Há fortes críticas ao uso do termo "geração", tendo em vista a concepção errônea que dela pode derivar, ao supor que as gerações se sucedem no tempo, como um tipo de melhoria, do que resultaria a substituição de uma geração por outra. Daí a opção de usar o termo "dimensão". A respeito da origem dessa tese, amplamente divulgada por Bobbio, ver CANÇADO Trindade Questiona a Tese de "Gerações de Direitos Humanos" de Norberto Bobbio. Apresentado no Seminário Direitos Humanos das Mulheres: A Proteção Internacional. Evento associado à V Conferência Nacional de Direitos Humanos. Dia 25 de maio de 2000. Câmara dos Deputados, Brasília, DF. Disponível em: <http://www. dhnet.org.br/direitos/militantes/cancadotrindade/cancado_bob.htm>. Acesso em: 08 dez. 2016. Para Bobbio, até chegar ao universalismo que culminou na Declaração da ONU, houve uma evolução do ponto de vista jurídico, se considerarmos que os direitos estabelecidos nas declarações anteriores (declaração francesa e declaração norte-americana), de influência jusnaturalista, eram direitos naturais, universais, que perderam a universalidade para ganhar em eficácia com a positivação, por ocasião da independência daqueles Estados, já que tinham validade apenas nos Estados que os adotaram em seu sistema jurídico. Deixaram, portanto, de ser direitos do homem para se tornarem direitos do cidadão; o que se busca hoje, portanto, seria a universalização positiva, em que direitos universais são positivados em cada nação, tornando-se "direitos do homem enquanto direitos do cidadão do mundo. BOBBIO, Norberto. A era dos direitos. Tradução Carlos Nelson Coutinho. Rio de Janeiro: Campus, 1992. p. 28-31.

${ }^{18}$ Seguindo a tese da geração, identificados com o princípio da fraternidade são os direitos de terceira geração: o direito à paz, ao meio ambiente, à qualidade de vida e ao desenvolvimento, ditos direitos de solidariedade, que se referem a povos e não mais a indivíduos, numa perspectiva humanitária. Para outra crítica da tese das gerações, ver LIMA, George Marmelstein. Críticas à teoria das gerações (ou mesmo dimensões) dos direitos fundamentais. Revista Opinião Jurídica, Fortaleza, Faculdade Christus, v. 2, n. 3, p. 171-182, 2004. Disponível em: <http://www.lexml.gov.br/urn/urn:lex:br:rede.virtual.bibliotecas:artigo. revista:2004;1000774136>. Acesso em: 12 dez. 2017. Para Laffer, tais direitos são fruto da mobilização nos países do "Terceiro Mundo" (grupo dos 77), a partir da distância entre teoria e prática no respeito aos direitos humanos nos territórios de colonização europeia. LAFER, Celso. A ONU e os Direitos humanos. Estudos Avançados, São Paulo, v. 9, n. 25, p. 176, set./dez. 1995. Disponível em: <http://www.scielo. br/pdf/ea/v9n25/v9n25a14.pdf>. https://doi.org/10.1590/S0103-40141995000300014. A polarização ideológica entre Estados Unidos e URSS teria levado o "Terceiro Mundo" a propor direitos que refletissem uma identidade cultural coletiva. Nesse sentido, torna-se pertinente a contribuição da teoria crítica dos direitos humanos desenvolvida por Flores, que expõe a historicidade dos direitos e seu caráter ideológico. HERRERA FLORES, Joaquín. A reinvenção dos direitos humanos. Florianópolis: Boiteux, 2009.

${ }^{19} \mathrm{BOBBIO}$, Norberto. A era dos direitos, cit., p. 33. 
implicam deveres de ação, que constituem prestações positivas por parte do Estado na forma de políticas públicas dirigidas aos mais fracos ${ }^{20}$.

A diferença na compreensão dos direitos expressa o tradicional conflito entre a liberdade do indivíduo e o poder do Estado, no âmbito do debate sobre os limites do poder e das funções do Estado moderno. Segundo entendimento de Bobbio, a liberdade em relação ao Estado é a liberdade no sentido predominante da doutrina liberal, isto é, o sentido negativo da liberdade de não estar obrigado a fazer o que não deseja, nem impedido de fazer o que deseja ${ }^{21}$. Assim sendo, o que se observa na forma como os Estados capitalistas e socialistas interpretaram os direitos de primeira e segunda geração é a contraposição entre um Estado liberal, que pouco intervém na esfera privada do indivíduo e valoriza sua liberdade, e um Estado social, cuja intervenção é exigida a fim de assegurar direitos iguais a todos.

Por outro lado, os pactos asseguravam ainda o direito dos povos à autodeterminação, isto é, os povos "determinam livremente seu estatuto político e asseguram livremente seu desenvolvimento econômico, social e cultural" 22 . Nesse sentido, pode-se entender o lapso de quase 20 anos entre a aprovação da DUDH e a adoção dos pactos. Mesmo assim, o protocolo dos direitos civis e políticos foi apresentado simultaneamente ao pacto, em 1966, e entrou em vigor em 1976, mas o protocolo do Pidesc só foi apresentado em 2008 e entrou em vigor apenas em 2013.

Lafer reconhece nesse processo o desenvolvimento de uma hierarquização de direitos:

O fato de um país pertencer a um dos blocos levava-o a aplicar e a promover seletivamente determinada categoria de direitos e a negligenciar a observância de outros. Os países em desenvolvimento, por seu turno, utilizavam o atraso econômico como justificativa de violações de direitos humanos em seus territórios ${ }^{23 .}$

\footnotetext{
${ }^{20}$ Disso resulta a distinção entre "liberdades", como os direitos garantidos pela não intervenção do Estado, e "poderes", como os direitos que exigem sua intervenção, o que pode gerar incompatibilidades (Id. Ibid., p. 43). Não intervenção, no entanto, não significa ausência de políticas públicas, pois, por exemplo, cabe ao Estado implementar políticas de segurança pública para garantir o direito à propriedade e à segurança. ${ }^{21}$ BOBBIO, Norberto. Liberalismo e democracia. Tradução Marco Aurélio Nogueira. São Paulo: Brasiliense, 2005. A respeito da necessidade da liberdade positiva no sentido da autonomia kantiana para exigir do cidadão que faça escolhas saudáveis como um dever moral, ver SOARES, Sônia. Ética da alimentação: porque devemos, segundo Kant, escolher uma alimentação adequada e saudável. 2015. Tese (Doutorado em Filosofia) - Universidade Federal do Rio Grande do Norte, Natal, 2015.

${ }^{22}$ Art. $1^{\circ}$, do Pidesc; art. $1^{\circ}$ do Pidcp. A autodeterminação é fundamental para a garantia da soberania alimentar, conforme estabelece a Lei Orgânica de Segurança Alimentar e Nutricional (LOSAN), em seu art. 5. BRASIL. Lei n. 11.346, de 15 de setembro de 2006. Lei Orgânica de Segurança Alimentar e Nutricional. Cria o Sistema Nacional de Segurança Alimentar e Nutricional - SISAN com vistas em assegurar o direito humano à alimentação adequada e dá outras providências. Disponível em: <http://www.planalto.gov.br/ ccivil_03/_ato2004-2006/2006/lei/l11346.htm>. Acesso em: 10 dez. 2016.

${ }^{23}$ LAFER, Celso. op. cit. p. 179.
} 
A demora em ratificar os pactos pode ser atribuída também à relutância dos governos em submeter sua situação interna, no que se refere aos direitos humanos, à supervisão internacional ${ }^{24}$, na medida em que, reconhecido o direito, é inevitável sua exigibilidade. Afinal, os direitos humanos nasceram como um tema de interesse internacional e exigiam a implantação de medidas para a garantia dos direitos firmados nos pactos, quando adotados por cada nação ${ }^{25}$. Assinado o pacto, mesmo sem protocolo, o Estado signatário se compromete a apresentar à ONU relatórios sobre as medidas adotadas para assegurar os direitos afirmados naquele instrumento ${ }^{26}$. No sistema jurídico brasileiro, o Pidesc foi promulgado em $1992^{27}$, mas somente a partir de 2010 a alimentação foi reconhecida como direito fundamental, no rol dos direitos sociais previstos no artigo 6º da Constituição Federal de $1988(\mathrm{CF} / 1988)^{28}$. O Brasil, até o momento, não assinou o protocolo do Pidesc.

\section{A realização do direito humano à alimentação adequada: uma crítica à progressividade}

Não há necessidade aqui de abordar todos os documentos e eventos posteriores à DUDH que ratificaram o direito à alimentação no âmbito internacional, mas certamente é preciso partir do artigo 11 do Pidesc, que assim estabelece:

$\$ 1^{\circ}$ Os Estados-partes no presente Pacto reconhecem o direito de toda pessoa a um nível de vida adequado para si próprio e para sua família, inclusive à alimentação, vestimenta e moradia adequadas $[\ldots]$

$\$ 2^{\circ}$ Os Estados-partes no presente Pacto, reconhecendo o direito fundamental de toda pessoa de estar protegida contra a fome, adotarão, individualmente e mediante cooperação internacional, as medidas, inclusive programas concretos que se façam necessários para:

1. Melhorar os métodos de produção, conservação e distribuição de gêneros alimentícios pela plena utilização dos conhecimentos técnicos e científicos, pela difusão de princípios de educação nutricional e pelo aperfeiçoamento ou reforma dos regimes

${ }^{24}$ LAFER, Celso. op. cit., p. 177.

${ }^{25} \mathrm{O}$ sistema internacional convive com sistemas regionais e locais de proteção aos direitos humanos que se complementam. Cf. PIOVESAN, Flávia. Direitos sociais, econômicos e culturais e direitos civis e políticos. Sur, Rev. int. direitos human, v. 1, n. 1, p. 20-47, 2004. ISSN 1983-3342. Disponível em: <http://www.scielo.br/pdf/ sur/v1n1/a03v1n1.pdf>. http://dx.doi.org/10.1590/S1806-64452004000100003. Acesso em: 08 jan. 2017.

${ }^{26}$ Art. $16, \S 1^{\circ}$, do Pidesc. Desde que ratificou o PIDESC, em 1992, o Brasil já apresentou três relatórios ao Comitê da ONU, nos anos de 2002, 2007 e 2014.

${ }^{27}$ BRASIL. Decreto n. 591 de 06 de julho de 1992. Promulga o PIDESC. Disponível em: <http://www.planalto. gov.br/ccivil_03/decreto/1990-1994/d0591.htm>. Acesso em: 08 dez. 2016.

${ }^{28}$ BRASIL. Constituição da República Federativa do Brasil de 1988. Disponível em: <http://www.planalto.gov. br/ccivil_03/constituicao/constituicaocompilado.htm>. Acesso em: 20 nov. 2016. 
agrários, de maneira que se assegurem a exploração e a utilização mais eficazes dos recursos naturais;

2. Assegurar uma repartição equitativa dos recursos alimentícios mundiais em relação às necessidades, levando-se em conta os problemas tanto dos países importadores quanto dos exportadores de gêneros alimentícios ${ }^{29}$. (Destaques nossos)

O Pidesc reafirma a alimentação como parte de um campo maior de direitos, uma condição para o exercício do direito em um "nível de vida adequado", revelando a interdependência entre os direitos. De acordo com o parágrafo $1^{\circ}$ do artigo citado, todos têm direito à alimentação adequada. Por conseguinte, respeitar tal direito já implicaria resolver a questão da fome, abordada no parágrafo $2^{\circ}$, afinal, posso estar livre da fome e não ter alimentação adequada, mas não posso ter alimentação adequada e ter fome.

No entanto, no contexto da separação dos direitos em categorias distintas, o parágrafo $1^{\circ}$ do artigo $2^{\circ}$ do Pidesc estabelece como compromisso dos Estados-Membros adotar medidas, "até o máximo de seus recursos disponíveis, que visem a assegurar, progressivamente, por todos os meios apropriados, o pleno exercício dos direitos”. Igualmente, o Comentário Geral n. 3 (CG3/1990), que trata das obrigações dos Estados-Partes quanto à garantia dos direitos sociais previstos no parágrafo $1^{\circ}$ do artigo $2^{\circ}$ do Pidesc, reconhece que a realização progressiva está ligada à limitação de recursos disponíveis e que, "enquanto a completa realização de direitos relevantes pode ser alcançada progressivamente, providências em direção ao objetivo devem ser tomadas dentro de um tempo razoavelmente curto depois da entrada em vigor do Pacto" ${ }^{30}$.

Ora, uma das obrigações dos Estados previstas neste documento é "garantir que direitos relevantes serão exercidos sem discriminação" ${ }^{\prime 1}$ (art. $1^{\circ}$ ). O direito à alimentação adequada, certamente, é um direito relevante. Mesmo assim, segundo a interpretação da ONU, admite-se a progressividade em sua realização, tendo em vista os recursos disponíveis de cada Estado que poderiam impossibilitar a plena realização do direito em um curto espaço de tempo. Por outro lado, adota-se um núcleo mínimo de obrigações, uma das quais se refere a impedir que "qualquer número significativo de indivíduos”32 (art. 10) seja privado de gêneros alimentícios

\footnotetext{
${ }^{29}$ Art. 11, Pidesc.

${ }^{30}$ ORGANIZAÇÃO DAS NAÇÕES UNIDAS - ONU. Compilação de instrumentos internacionais de direitos humanos. Provedoria dos Direitos Humanos e Justiça. 1. ed. Disponível em: <http://acnudh.org/wpcontent/uploads/2011/06/Compilation-of-HR-instruments-and-general-comments-2009-PDHJTimorLeste-portugues.pdf>. Acesso em: 10 dez. 2016. Comentário Geral n. 3: Implementação a nível nacional $\left(\right.$ artigo $2^{\circ}$ ). p. 106.

${ }^{31}$ Id. Ibid. p. 106.

${ }^{32}$ Id. Ibid. p. 108.
} 
essenciais; nestas circunstâncias, cada Estado deve buscar o máximo de esforços, inclusive a cooperação internacional.

Para criticar a progressividade na realização do direito humano à alimentação adequada, no âmbito da própria ONU, resgata-se aqui o documento proclamado pela Conferência Internacional de Direitos Humanos realizada em Teerã em 1968 para avaliar os 20 anos da DUDH, cujo avanço mais importante foi exatamente explicitar a ideia de indivisibilidade dos direitos: "Como os direitos humanos e as liberdades fundamentais são indivisíveis, a realização dos direitos civis e políticos sem o gozo dos direitos econômicos, sociais e culturais resulta impossível”33 $\left(\$ 3^{\circ}\right)$. Corroborando esse pensamento, na Conferência Mundial para os Direitos Humanos ${ }^{34}$ realizada em Viena em 1993 - convocada pela ONU logo após a queda do muro de Berlim -, a Declaração e Programa de Ação de Viena (DPAV) reconhece na fome um obstáculo à realização de todos os direitos humanos (art. 30), os quais, junto com as liberdades individuais, são direitos naturais aos seres humanos e cuja proteção e promoção são responsabilidades primordiais dos governos $\left(\operatorname{art} .1^{\circ}\right) . \mathrm{O}$ texto defende que "a falta de desenvolvimento não pode ser invocada para justificar limitações aos (outros) direitos humanos reconhecidos internacionalmente" ${ }^{35}$ (art. 10)

Jean Ziegler ${ }^{36}$, ex-relator da ONU para o relatório sobre o direito humano à alimentação adequada, adverte que a progressividade não pode ser usada para justificar situações persistentes de injustiça, incluindo a discriminação de qualquer tipo. Seria o caso daquelas situações de fome em que famintos não têm escolha e são obrigados a aceitar qualquer alimento, uma espécie de discriminação negativa, em que aos que nada têm é assegurado o pior, algo absolutamente incompatível com a defesa dos direitos humanos, já que todas as pessoas têm a mesma dignidade.

\footnotetext{
${ }^{33}$ ORGANIZAÇÃO DAS NAÇÕES UNIDAS - ONU. Conferência Internacional de Direitos Humanos, Teerã, 1968. Disponível em: <http://www.dhnet.org.br/direitos/sip/onu/doc/teera.htm>. Acesso em: 08 dez. 2016. Para uma crítica à forma de redação deste parágrafo, que possibilitou interpretar a indivisibilidade como condicionalidade para os direitos civis e políticos, ver ALVES, J. A. Lindgren. A atualidade retrospectiva da Conferência de Viena sobre direitos humanos. Disponível em <http://www.pge.sp.gov.br/centrodeestudos/ revistaspge/revista53/atualidade.htm>. Acesso em: 02 maio 2017.

${ }^{34} \mathrm{O}$ Brasil teve destaque na Conferência de Viena porque o embaixador Gilberto Saboia presidiu o Comitê de Redação. Sobre o ostracismo da Conferência de Teerã ver HERNANDEZ, Matheus de Carvalho. Os direitos humanos como temática global e a soberania no sistema internacional pós-Guerra Fria: a Conferência de Viena. 2010. p. 28. Dissertação (Mestrado em Ciências Sociais) - Faculdade de Filosofia e Ciências, Universidade Estadual Paulista, Marília, 2010. Disponível em: <https://repositorio.unesp.br/bitstream/ handle/11449/88766/hernandez_mc_me_mar.pdf?sequence=1\&isAllowed=y>.

${ }^{35}$ ORGANIZAÇÃO DAS NAÇÕES UNIDAS - ONU. Declaração de Viena e Programa de Ação. Disponível em: <http://www.dhnet.org.br/direitos/anthist/viena/viena.html>. Acesso em: 10 maio 2017. Trata-se da vedação ao retrocesso.

${ }^{36}$ UNITED NATIONS - UN. Human Rights. Office of the High Comissioner. Special Rapporteur on the right to food. p. 10. Disponivel em: <https://www.ohchr.org/Documents/Publications/FactSheet27en.pdf>. Acesso em: 31 ago. 2018.
} 
Para Lafer" a Conferência de Viena "favorece a subordinação das soberanias à ética dos princípios representados pelos direitos humanos". Sobre o que considera a marca kantiana na evolução dos direitos humanos, o autor diz o seguinte:

Os direitos humanos [...] tornaram-se, com base na Carta, no mundo pós-Guerra Fria, um tema global, à maneira kantiana. Representam o reconhecimento axiológico do ser humano como fim, e não meio; tendo direito a um lugar no mundo; um mundo que encontra um terreno comum entre a Ética e a Política através da associação convergente de três grandes temas: direitos humanos e democracia no plano interno e paz no plano internacional ${ }^{38}$. (Destaques nossos.)

A marca kantiana pode ser lida, no preâmbulo da DUDH, nas palavras "liberdade" "dignidade" e "lei". Considerar a pessoa humana como fim é o cerne do imperativo categórico na moral kantiana ${ }^{39}$, também presente no direito de humanidade em sua doutrina do direito: "Não faças de ti mesmo apenas um meio para os outros, mas sejas simultaneamente um fim para eles" ${ }^{40}$.

É importante observar que o artigo $5^{\circ}$ da Declaração de Viena reafirma os traços fundamentais para a defesa dos direitos humanos: a universalidade, a indivisibilidade, a interdependência e inter-relação. A universalidade já era explicitada no artigo $1^{\circ}$ da DUDH. Quanto aos outros três princípios, segue-se aqui a análise de Daly ${ }^{41}$, para quem entender o significado de interdependência e inter-relação permite colocar em evidência o significado distinto da indivisibilidade. Grosso modo, a autora situa a inter-relação no campo das relações mais genéricas entre direitos, do tipo familiar ou genealógica - por exemplo, todos os direitos humanos estão inter-relacionados porque derivam do reconhecimento da dignidade humana inerente a todos os membros da família humana. No caso da interdependência, a relação seria mais de funcionalidade, ou seja, um direito não funciona sem o outro, sendo, por isso, sinérgicos - por exemplo, o direito à saúde e o direito à vida têm relação de interdependência com o direito à alimentação. Já quanto à indivisibilidade, a autora aponta que se trata de um conceito muito mais forte, pois descreve a natureza integral de um bloco de direitos humanos. A indivisibilidade permitiria ver que muitos direitos são, na verdade, um bloco único de direitos ${ }^{42}$.

\footnotetext{
${ }^{37}$ LAFER, Celso. op. cit., p. 182.

${ }^{38}$ Id. Ibid., p. 172.

${ }^{39}$ KANT, Immanuel. Fundamentação da metafisica dos costumes. Tradução Paulo Quintela. Lisboa: 70, 2014. (Coleção "Textos filosóficos").

${ }^{40} \mathrm{KANT}$ Immanuel. A metafísica dos costumes. Tradução de Edson Bini. Bauru: Edipro, 2003. p. 82.

${ }^{41}$ DALY, Erin. Environmental human rights: paradigm of indivisibility. Widener Law School Legal Studies Research Paper Series n. 11-05, Widener University School of Law, Delaware, United States, 2011. p. 2. Disponivel em <https://ssrn.com/abstract=1743610>. Acesso em: 10 jan. 2017.

${ }^{42} \mathrm{~A}$ autora faz analogia entre o bloco dos direitos humanos e um diamante, em que nenhuma face pode ser separada do diamante, e o diamante não existe sem suas facetas múltiplas. Id. Ibid., p. 4.
} 
A Declaração de Viena tentou, ainda, eliminar aquelas diferenças que levaram à elaboração dos dois pactos ${ }^{43}$ separadamente, ao afirmar que "é dever dos Estados promover e proteger todos os direitos humanos e liberdades fundamentais, sejam quais forem seus sistemas políticos, econômicos e culturais" (art. $5^{\circ}$ ).

Diante da dificuldade para a realização progressiva do direito humano à alimentação adequada, os Estados-Membros, por ocasião da Cúpula Mundial da Alimentação (1996), solicitaram um esclarecimento ao Comitê de Direitos Econômicos, Sociais e Culturais do Alto Comissariado das Nações Unidas para os Direitos Humanos, o qual elaborou o documento Comentário Geral n. 12. Reconhecendo que, "fundamentalmente, as raízes do problema da fome e da desnutrição não residem na falta de alimento, mas na falta de acesso ao alimento disponível, entre outras razões por causa da pobreza de grandes segmentos da população mundial" ${ }^{44}$ (art. 12), o documento assim esclareceu o conteúdo normativo do artigo 11 do Pidesc:

O direito à alimentação adequada realiza-se quando cada homem, mulher e criança, sozinho ou em companhia de outros, tem acesso físico e econômico, ininterruptamente, à alimentação adequada ou aos meios para sua obtenção. O direito à alimentação adequada não deverá, portanto, ser interpretado em um sentido estrito ou restritivo, que o equaciona em termos de um pacote mínimo de calorias, proteínas e outros nutrientes específicos. O direito à alimentação adequada terá de ser resolvido de maneira progressiva. No entanto, os Estados têm a obrigação precípua de implementar as ações necessárias para mitigar e aliviar a fome, como estipulado no parágrafo $2^{\circ}$ do artigo 11 , mesmo em épocas de desastres, naturais ou não $0^{45}$ (art. $\left.6^{\circ}\right)$. (Destaques nossos.)

Como se vê, na questão da aplicabilidade, o documento ratifica a ideia de progressividade ${ }^{46}$ no compromisso dos Estados de adoção de medidas que assegurem o pleno exercício dos direitos ali reconhecidos, admitindo que: "A obrigação

\footnotetext{
${ }^{43}$ O Comentário Geral n. 3 afirma a "neutralidade" do PIDESC no § 8: “Em termos de sistemas políticos e econômicos, o Pacto é neutro e seus princípios não podem ser precisamente descritos como sendo afirmados exclusivamente sobre a necessidade ou a conveniência de sistema capitalista ou socialista ou misto [...]. [...] os direitos reconhecidos no Pacto são suscetíveis de realização dentro do contexto de uma ampla variedade de sistemas econômicos e políticos, com a única condição de que a interdependência e a indivisibilidade dos dois grupos de direitos humanos, como afirmado entre outros no preâmbulo do Pacto, sejam reconhecidas e refletidas no sistema em questão." ORGANIZAÇÃO DAS NAÇÕES UNIDAS - ONU. Compilação de instrumentos internacionais de direitos humanos, cit., Comentário Geral n. 3: Implementação a nível nacional (artigo $2^{\circ}$ ), cit., p. 107.

${ }^{44}$ ORGANIZAÇÃ̃O DAS NAÇÕES UNIDAS - ONU. Compilação de instrumentos internacionais de direitos humanos, cit., Comentário Geral n. 12.

${ }^{45}$ Id. Ibid.

${ }^{46}$ FOOD AND AGRICULTURE ORGANIZATION OF THE UNITED NATIONS - FAO. Voluntary guidelines to support the progressive realization of the right to adequate food in the context of national food security. Adopted by the 127th Session of the FAO Council November 2004. Roma, 2005. Disponivel em <http://www.fao. org/3/a-y7937e.pdf>. Acesso em: 20 mar. 2017.
} 
principal é aquela de adotar medidas para que se alcance, de forma progressiva, a total realização do direito à alimentação adequada. Isto impõe a obrigação de que isto seja feito de forma tão rápida quanto possível"47 (art. 14). Nesse caminho, o mínimo é garantir que todos estejam livres da fome.

Ocorre que proteger da fome não implica a garantia de alimentos adequados, o que poderia parecer aceitável em nome da suposta progressividade na realização do direito humano à alimentação adequada. A pessoa humana, que é sujeito portador de dignidade intrínseca e de direitos, é merecedora de uma alimentação igualmente digna e tem direito a alimentos adequados em qualquer momento de sua existência, conforme estabelece o referido documento ao defender uma interpretação do direito humano à alimentação adequada não limitada ao aporte nutricional.

O Comentário Geral n. 2 ainda vai de encontro à ideia de progressividade: ao abordar o conteúdo essencial do direito humano à alimentação adequada, expresso na noção de sustentabilidade do acesso e da disponibilidade, afirma que a acessibilidade sustentável não deve impedir "a fruição de outros direitos humanos" ${ }^{48}$ (art. $8^{\circ}$ ), o que é compatível com a ideia original de inter-relação e interdependência dos direitos humanos. Por conseguinte, o comentário parece contraditório, ao reconhecer a alimentação adequada como direito humano, portanto inerente à dignidade humana, ao mesmo tempo em que adota a progressividade, corroborando a distinção entre direitos de aplicação imediata e os de aplicação progressiva como se, de imediato, fosse aceita apenas a obrigação de aliviar a fome, deixando para depois a exigibilidade do direito à alimentação adequada. Se o fundamento de todo direito humano é a dignidade - um valor único porque a pessoa humana é indivisível -, não faria sentido dividir direitos para realizá-los em momentos diferentes.

Além da contradição, há duas questões em aberto no Comentário Geral n. 12, que buscava justamente esclarecer o conteúdo normativo do direito humano à alimentação: a primeira diz respeito a quando será "tão rápido quanto possível” para garantir o acesso de todos a alimentos adequados, ou seja, quanto tempo deve-se esperar entre realizar o parágrafo $2^{\circ}$ e realizar o parágrafo $1^{\circ}$. Que a fome tem pressa parece ser um consenso, mas a alimentação adequada para todos poderia esperar? Com qual justificativa? A segunda questão é sobre qual alimento deve ser usado para acabar com a fome. É aceitável realizar o parágrafo $2^{\circ}$ do artigo 11 - proteger contra a fome - sem realizar simultaneamente o parágrafo $1^{\circ}$, oferecendo alimentos não saudáveis ${ }^{49}$ ? Nesse caso, estaria sendo estabelecida

\footnotetext{
${ }^{47}$ ORGANIZAÇÃO DAS NAÇÕES UNIDAS - ONU. Compilação de instrumentos internacionais de direitos humanos, cit., Comentário Geral n. 12.

${ }^{48}$ Id. Ibid.

${ }^{49} \mathrm{~A}$ esse respeito, ver o caso da ajuda humanitária por meio de sementes transgênicas oferecida à população faminta da Zâmbia. ZIEGLER, Jean. Destruição em massa: geopolítica da fome. Tradução de José Paulo Netto. São Paulo: Cortez, 2013. Vandana Shiva considera este um caso de ajuda alimentar "desumana", que faz de pessoas famintas meras cobaias das corporações de sementes transgênicas. Cf. SHIVA,
} 
uma distinção entre grupos populacionais, uns com o direito do parágrafo $1^{\circ} \mathrm{e}$ outros com o direito do parágrafo $2^{\circ}$. Isso seria compatível com a dignidade do sujeito de direitos? Seria possível dividir o direito à alimentação em duas porções, sendo que uma é completa e a outra, não?

Por último, vê-se outra incoerência na forma como a ONU tem tratado os direitos humanos, baseada nessa distinção entre realização imediata e progressiva. Em relação ao direito à vida, inicialmente, o Pidcp admitia a aplicação da pena capital "em decorrência de uma sentença transitada em julgado e proferida por tribunal competente" (art. $6^{\circ}, \$ 2^{\circ}$ ); posteriormente, passou a reconhecer a pena de morte como grave exceção àquele direito proposto na $\mathrm{DUDH}^{50}$. Teria a ONU reconhecido progressividade na realização do direito à vida?

Diante disso, na situação atual, torna-se logicamente contraditório o Pidcp defender a aplicação imediata do direito à vida e o Pidesc defender a realização progressiva do direito à alimentação, porque não existe vida sem alimento ${ }^{51}$. Não se pode considerar digna do ser humano livre pensado na DUDH a vida vivida no lapso de tempo em que o sujeito de direitos espera pelo acesso à alimentação adequada, como é o caso de milhões de pessoas em todo o mundo, inclusive no Brasil, como exemplificado a seguir.

\section{A realização imediata do direito humano à alimentação adequada: uma defesa da dignidade da pessoa humana}

A despeito da distinção histórica entre os direitos humanos - quanto à sua positivação -, há que se reconhecer a permanência do seu fundamento jurídico na dignidade da pessoa humana, como afirmara a DUDH. Por este motivo, como expressão da dignidade humana, os direitos fundamentais gozam do efeito cliquet $^{52}$, um postulado de proteção máxima que veda o retrocesso, uma vez admitidos tais direitos.

Defendeu-se a insustentabilidade da tese que faz distinção entre imediata e progressiva aplicabilidade dos direitos humanos, a partir de contradições nos

Vandana. Why I must believe sending GMOs to starving people is inhuman aid. Disponivel em <http:// stopogm.net/sites/stopogm.net/files/InhumanAid.pdf>. Acesso em: 10 jan. 2017.

${ }^{5}$ ORGANIZAÇÃO DAS NAÇÕES UNIDAS - ONU. Segundo Protocolo Opcional ao PIDCP com vista à abolição da pena de morte. Disponível em: <http://www.dhnet.org.br/direitos/sip/onu/pmorte/lex151.htm>. Acesso em: 10 maio 2015. O retorno da pena de morte foi vetado nos países nos quais ela já tinha sido abolida pela Convenção Americana sobre Direitos Humanos, de 1969. O Protocolo Adicional à Convenção Americana sobre Direitos Humanos referente à abolição da pena de morte (1990) admite a reserva em tempo de guerra.

${ }^{51} \mathrm{~A}$ alimentação pode ser considerada um direito anterior ao direito de liberdade, tão intrínseco que, antes mesmo de ser possível a liberdade, já está lá, se pensarmos na vida intrauterina que também precisa do alimento. SOARES, Sônia. op. cit.

${ }^{52}$ Termo francês usado por alpinistas para designar aquele ponto da escalada a partir do qual não é mais possível retroceder, devendo-se seguir sempre para cima. O Pidesc assegura a vedação do retrocesso em seu art. $5^{\circ}, \S 2^{\circ}$. 
documentos da ONU. Nas palavras de Flávia Piovesan" "Sob a ótica normativa internacional, está definitivamente superada a concepção de que os direitos sociais, econômicos e culturais não são direitos legais. A ideia da não acionabilidade dos direitos sociais é meramente ideológica, e não científica”.

Diante do perfil nutricional brasileiro, apontam-se agora as implicações da aceitação da progressividade na realização do direito humano à alimentação adequada, prevista na Política e no Plano de Segurança Alimentar e Nutricional ${ }^{54}$.

O caso brasileiro é paradoxal: ao mesmo tempo em que atingiu o "Objetivo do Milênio" na questão de redução da fome, expõe a maior parte da população de baixa renda e escolaridade a alimentos nada saudáveis, do que resultam mortes e doenças evitáveis ${ }^{55}$. Faz-se necessário recordar as obrigações dos Estados para a garantia do direito humano à alimentação adequada estabelecidas no Comentário Geral n. 12 (art. 15):

A obrigação de respeitar o acesso existente à alimentação adequada requer que os Estados-Partes não tomem quaisquer medidas que resultem no bloqueio deste acesso. A obrigação de proteger requer que medidas sejam tomadas pelo Estado para assegurar que empresas ou indivíduos não privem outros indivíduos de seu acesso à alimentação adequada. A obrigação de satisfazer (facilitar) significa que o Estado deve envolver-se proativamente em atividades destinadas a fortalecer o acesso de pessoas a recursos e meios, e a utilização dos mesmos, de forma a garantir o seu modo de vida, inclusive a sua segurança alimentar, e a utilização destes recursos e meios por estas pessoas. Finalmente,

\footnotetext{
${ }^{53}$ PIOVESAN, Flávia. op. cit., p. 26.

${ }^{54}$ Art. 21. BRASIL. Decreto n. 7272, de 25 de agosto de 2010. Regulamenta a Lei n. 11.346, de 15 de setembro de 2006, que cria o Sistema Nacional de Segurança Alimentar e Nutricional - SISAN com vistas a assegurar o direito humano à alimentação adequada, institui a Política Nacional de Segurança Alimentar e Nutricional - PNSAN, estabelece os parâmetros para a elaboração do Plano Nacional de Segurança Alimentar e Nutricional, e dá outras providências. Disponível em: <http://www.planalto.gov.br/ccivil_03/_ ato2007-2010/2010/decreto/d7272.htm>. Acesso em: 31 ago. 2018. O II Plano Nacional de Segurança Alimentar e Nutricional (2016) informa que apenas 12 estados têm planos de segurança alimentar e nutricional, ao mesmo tempo em que reconhece avanços no acesso à alimentação como resultado das ações de enfrentamento da fome e da pobreza (p. 16) e considera como um dos principais desafios a criação de um contexto favorável à adoção de hábitos alimentares mais saudáveis e adequados pela população brasileira (p. 18). CÂMARA INTERMINISTERIAL DE SEGURANÇA ALIMENTAR E NUTRICIONAL. CAISAN. II Plano Nacional de Segurança Alimentar e Nutricional (PLANSAN 2016-2019). Brasília, 2016. Disponivel em <https://www.mds.gov.br/webarquivos/arquivo/seguranca_alimentar/caisan/Publicacao/ Caisan_Nacional/BalancoPLANSAN2016_2019.pdf>.

${ }^{55}$ BRASIL. Ministério da Saúde. Secretaria de Vigilância em Saúde. Departamento de Análise de Situação de Saúde. Plano de ações estratégicas para o enfrentamento das doenças crônicas não transmissíveis (DCNT) no Brasil 2011-2022. Brasília: Ministério da Saúde, 2011. (Série Textos Básicos de Saúde). Sobre a realidade brasileira, o governo reconhece que "apenas 18,2\% consomem cinco porções de frutas e hortaliças em cinco ou mais dias por semana, 34\% consomem alimentos com elevado teor de gordura e $28 \%$ consomem refrigerantes 5 ou mais dias por semana" (ib. p.11).
} 
sempre que um indivíduo ou grupo está impossibilitado, por razões além do seu controle, de usufruir o direito à alimentação adequada com os recursos a sua disposição, os Estados têm a obrigação de satisfazer (prover) o direito diretamente. Esta obrigação também deve existir no caso de vítimas de desastres naturais ou provocados por causas diversas ${ }^{56}$.

Cabe ao Estado prover a população com alimentos adequados, respeitar seu acesso a estes, proteger a população de quem a impede deste acesso e promover práticas saudáveis de produção de alimentos, acesso e disponibilidade a todos. Não há como defender, portanto, que se resolva o problema da fome para, só depois, lutar por uma alimentação adequada.

Isso significa que, sendo vedado o retrocesso, no caso do direito humano à alimentação adequada seria mais coerente considerar que é uma grave exceção a este direito quando pessoas só têm acesso a alimentos não saudáveis, ainda que para evitar uma situação de fome - como é o caso brasileiro, em que saímos do mapa da fome para entrarmos no mapa epidêmico do sobrepeso e da obesidade ${ }^{57}$. Sair da fome mediante acesso a alimentos inadequados não parece uma "progressividade" na realização do direito humano à alimentação adequada, mas sim a manutenção do desrespeito a um direito humano fundamental. A defesa do direito à alimentação adequada deve ser, antes de tudo, a defesa da dignidade humana, não a da mera satisfação de necessidades fisiológicas, o que poderia ser feito, por exemplo, com rações balanceadas em forma de pó ou cápsulas. Além disso, como observa George $K e n t^{58}$ ao abordar a realização deste direito em relação às pessoas encarceradas, mesmo que sejam bem alimentadas do ponto de vista nutricional, não se pode dizer que elas têm seu direito à alimentação realizado, pois não podem influenciar no que comerão e como serão alimentadas.

Há, portanto, um conteúdo político na realização do direito humano à alimentação adequada, inseparável de seu conteúdo moral, e isto é reconhecido pela Organização das Nações Unidas para a Alimentação e a Agricultura (FAO) ${ }^{59}$, que

\footnotetext{
${ }^{56}$ ORGANIZAÇÃO DAS NAÇÕES UNIDAS - ONU. Compilação de instrumentos internacionais de direitos humanos, cit., Comentário Geral n. 12.

${ }^{57} \mathrm{~A}$ ONU faz alerta sobre a mudança no nosso perfil nutricional. AUMENTAM sobrepeso e obesidade no Brasil, aponta relatório de FAO e OPAS. ONUBR - Nações Unidas no Brasil, 14 jan. 2017 Disponível em <https:// nacoesunidas.org/aumentam-sobrepeso-e-obesidade-no-brasil-aponta-relatorio-de-fao-e-opas/>. Acesso em: 30 jan. 2017. No mundo, atualmente, cerca de 800 milhões de pessoas permanecem desnutridas, enquanto 600 milhões estão obesas.

${ }^{58}$ KENT, George. Freedom from want: the human right to adequate food. Washington, D.C.: Georgetown University Press, 2004. p. 46. Disponivel em <http://press.georgetown.edu/book/georgetown/freedomwant>. Acesso em: 05 jan. 2017.

${ }^{59}$ FOOD AND AGRICULTURE ORGANIZATION OF THE UNITED NATIONS - FAO. Voluntary guidelines to support the progressive realization of the right to adequate food in the context of national food security, cit. A participação e o controle social também são hoje uma diretriz da Política Nacional de Alimentação e Nutrição. BRASIL. Ministério da Saúde. Portaria n. 2.715, de 17 de novembro de 2011. Atualiza a Política
} 
estabelece a participação como princípio para a garantia deste direito. Analogamente à análise de $D a l y^{60}$, pode-se defender a unicidade do direito humano à alimentação adequada, rejeitando a visão de um direito com duas dimensões (a da fome $e$ a da alimentação adequada) separadas no tempo e cuja realização deva ser progressiva. Essa separação é incompatível com o fundamento dos direitos humanos, de modo que a defesa contrária à progressividade na realização deste direito é também a defesa da afirmação da indivisibilidade deste direito. Portanto, o que precisamos fazer é reconhecer a alimentação como direito social e também político e exigir sua realização.

\section{Considerações finais}

Retomou-se a tese da progressividade aplicada à realização do direito humano à alimentação adequada para expor a dificuldade em atender ao que estabelece o artigo 11 do PIDESC, quando se aceita que primeiro se resolva o problema da fome para, depois, exigir alimentos adequados, considerando que o perfil nutricional brasileiro traz uma complexidade que exige a imediata realização do direito humano à alimentação adequada em sua forma plena, assegurando que todos tenham o que comer e que essa alimentação acessível a todos seja adequada e saudável.

A despeito do avanço na garantia jurídica dos direitos humanos, nos dias atuais, para superar o desafio da progressividade e rejeitar qualquer retrocesso (já que o problema da fome não resulta da falta de alimento), é preciso exigir a intervenção do Estado na garantia desse direito. O Estado tem obrigações para com a realização do direito humano à alimentação adequada, e as pessoas não têm apenas uma necessidade fisiológica de alimento, mas também o direito de decidir sobre qual alimento plantar, produzir ou consumir, o que significa ter direito de participar da elaboração de políticas públicas e da regulação sobre alimentos. No momento em que planos estaduais de segurança alimentar e nutricional precisam ser elaborados no Brasil, a compreensão do caráter político do direito humano à alimentação adequada apresenta-se como fundamental para fortalecer a participação social nesse processo, no sentido de exigir a realização imediata deste direito.

\section{Referências}

ALVES, J. A. Lindgren. A atualidade retrospectiva da Conferência de Viena sobre direitos humanos. Disponível em <http://www.pge.sp.gov.br/centrodeestudos/revistaspge/revista53/ atualidade.htm>. Acesso em: 02 maio 2017.

Nacional de Alimentação e Nutrição. Disponível em: <http://bvsms.saude.gov.br/bvs/saudelegis/ gm/2011/prt2715_17_11_2011.html>. Acesso em: 31 ago. 2018.

${ }^{60}$ DALY, Erin. op. cit. 
AUMENTAM sobrepeso e obesidade no Brasil, aponta relatório de FAO e OPAS. ONUBR - Nações Unidas no Brasil, 14 jan. 2017 Disponível em < https://nacoesunidas.org/aumentamsobrepeso-e-obesidade-no-brasil-aponta-relatorio-de-fao-e-opas/>. Acesso em: 30 jan. 2017.

BOBBIO, Norberto. A era dos direitos. Tradução Carlos Nelson Coutinho. Rio de Janeiro: Campus, 1992.

. Liberalismo e democracia. Tradução Marco Aurélio Nogueira. São Paulo: Brasiliense, 2005.

BRASIL. Ministério da Saúde. Secretaria de Vigilância em Saúde. Departamento de Análise de Situação de Saúde. Plano de ações estratégicas para o enfrentamento das doenças crônicas não transmissíveis (DCNT) no Brasil 2011-2022. Brasília: Ministério da Saúde, 2011. (Série Textos Básicos de Saúde).

CÂMARA INTERMINISTERIAL DE SEGURANÇA ALIMENTAR E NUTRICIONAL. CAISAN. II Plano Nacional de Segurança Alimentar e Nutricional (PLANSAN 2016-2019). Brasília, 2016. Disponível em <https://www.mds.gov.br/webarquivos/arquivo/seguranca alimentar/caisan/Publicacao/Caisan_Nacional/BalancoPLANSAN2016_2019.pdf>.

CANÇADO Trindade Questiona a Tese de "Gerações de Direitos Humanos" de Norberto Bobbio. Apresentado no Seminário Direitos Humanos das Mulheres: A Proteção Internacional. Evento associado à V Conferência Nacional de Direitos Humanos. Dia 25 de maio de 2000. Câmara dos Deputados, Brasília, DF. Disponível em: <http://www.dhnet.org.br/direitos/ militantes/cancadotrindade/cancado_bob.htm>. Acesso em: $08 \mathrm{dez} .2016$.

CONVENÇÃO RELATIVA AO TRATAMENTO DOS PRISIONEIROS DE GUERRA. Disponível em: $<$ http://www.domtotal.com/direito/pagina/detalhe/22766/convencao-relativaao-tratamento-dos-prisioneiros-de-guerra>. Acesso em: 12 jan. 2017.

DALY, Erin. Environmental human rights: paradigm of indivisibility. Widener Law School Legal Studies Research Paper Series n. 11-05, Widener University School of Law, Delaware, United States, 2011. Disponível em <https://ssrn.com/abstract=1743610>. Acesso em: 10 jan. 2017.

FACING HISTORY AND OURSELVES. Social and Economic Rights: Eleanor's Speech at the Sorbonne. Disponível em: <https://www.facinghistory.org/universal-declaration-humanrights/social-and-economic-rights-eleanors-speech-sorbonne>. Acesso em: 31 ago. 2018.

FOOD AND AGRICULTURE ORGANIZATION OF THE UNITED NATIONS - FAO. Voluntary guidelines to support the progressive realization of the right to adequate food in the context of national food security. Adopted by the 127th Session of the FAO Council November 2004. Roma, 2005. Disponível em <http://www.fao.org/3/a-y7937e.pdf>. Acesso em: 20 mar. 2017.

GLOOBAL. Protocolo facultativo ao Pidesc: uma ferramenta para exigir os DESC. Disponível em: <http://www.gloobal.net/iepala/gloobal/fichas/ficha.php?entidad=Documentos\&id=17 987\&opcion=sumario $>$. Acesso em: 10 mar. 2017. 
HERNANDEZ, Matheus de Carvalho. Os direitos humanos como temática global e a soberania no sistema internacional pós-Guerra Fria: a Conferência de Viena. 2010. Dissertação (Mestrado em Ciências Sociais) - Faculdade de Filosofia e Ciências, Universidade Estadual Paulista, Marília, 2010. Disponível em: <https://repositorio.unesp.br/bitstream/handle/11449/88766/ hernandez_mc_me_mar.pdf?sequence $=1$ \&isAllowed $=y>$.

HERRERA FLORES, Joaquín. A reinvenção dos direitos humanos. Florianópolis: Boiteux, 2009.

KANT, Immanuel. Fundamentação da metafisica dos costumes. Tradução Paulo Quintela. Lisboa: 70, 2014. (Coleção “Textos filosóficos”).

. A metafísica dos costumes. Tradução de Edson Bini. Bauru: Edipro, 2003.

KENT, George. Freedom from want: the human right to adequate food. Washington, D.C.: Georgetown University Press, 2004. Disponivel em <http://press.georgetown.edu/book/ georgetown/freedom-want>. Acesso em: 05 jan. 2017.

LAFER, Celso. A ONU e os Direitos humanos. Estudos Avançados, São Paulo, v. 9, n. 25, p. 169-185, set./dez. 1995. Disponível em: <http://www.scielo.br/pdf/ea/v9n25/v9n25a14. pdf>. https://doi.org/10.1590/S0103-40141995000300014.

LIMA, George Marmelstein. Críticas à teoria das gerações (ou mesmo dimensões) dos direitos fundamentais. Revista Opinião Jurídica, Fortaleza, Faculdade Christus, v. 2, n. 3, p. 171-182, 2004. Disponível em: <http://www.lexml.gov.br/urn/urn:lex:br:rede.virtual.bibliotecas:artigo. revista:2004;1000774136>. Acesso em: 12 dez. 2017.

NATIONALHOMELESS.ORG. New report: the criminalization of food-sharing practices. Disponível em: <http://nationalhomeless.org/new-report-criminalization-food-sharingpractices $>$. Acesso em: 31 ago. 2018.

ORGANIZAÇÃO DAS NAÇÕES UNIDAS - ONU. Compilação de instrumentos internacionais de direitos humanos. Provedoria dos Direitos Humanos e Justiça. 1. ed. Disponível em: <http:// acnudh.org/wp-content/uploads/2011/06/Compilation-of-HR-instruments-and-generalcomments-2009-PDHJTimor-Leste-portugues.pdf>. Acesso em: 10 dez. 2016.

. Conferência Internacional de Direitos Humanos, Teerã, 1968. Disponível em: <http:// www.dhnet.org.br/direitos/sip/onu/doc/teera.htm>. Acesso em: 08 dez. 2016.

ORGANIZACIÓN DE LAS NACIONES UNIDAS PARA LA AGRICULTURA Y LA ALIMENTACIÓN - FAO. Guía para legislar sobre el derecho a la alimentación. Disponível em: <http://www.fao.org/docs/eims/upload/296437/Guide_on_legislating_ES.pdf >. Acesso em: 31 ago. 2018.

PIOVESAN, Flávia. Direitos sociais, econômicos e culturais e direitos civis e políticos. Sur, Rev. int. direitos human, v. 1, n. 1, p. 20-47, 2004. ISSN 1983-3342. Disponível em: <http://www. scielo.br/pdf/sur/v1n1/a03v1n1.pdf>. http://dx.doi.org/10.1590/S1806-64452004000100003. Acesso em: 08 jan. 2017. 
SHIVA, Vandana. Why I must believe sending GMOs to starving people is inhuman aid. Disponivel em <http://stopogm.net/sites/stopogm.net/files/InhumanAid.pdf $>$. Acesso em: 10 jan. 2017.

SOARES, Sônia. Ética da alimentação: porque devemos, segundo Kant, escolher uma alimentação adequada e saudável. 2015. Tese (Doutorado) - Universidade Federal do Rio Grande do Norte, Natal, 2015.

UNITED NATIONS - UN. Draft International Covenants on Human Rights: Annotation. Prepared by the Secretary-General. Chapter II (12). Disponível em: $<$ http://repository.un.org/ handle/11176/302618>. Acesso em: 20 jan. 2017.

Human Rights. Office of the High Comissioner. Special Rapporteur on the right to food. Disponível em: <https://www.ohchr.org/Documents/Publications/FactSheet27en.pdf $>$. Acesso em: 31 ago. 2018.

International Covenant on Economic, Social and Cultural Rights. New York, 16 Dec. 1966. Disponível em: <https://treaties.un.org/Pages/ViewDetails.aspx?src=IND\&mtdsg no $=I V-3 \&$ chapter $=4 \&$ lang=en $>$. Acesso em: 24 jan. 2017.

ZIEGLER, Jean. Destruição em massa: geopolítica da fome. Tradução de José Paulo Netto. São Paulo: Cortez, 2013.

Sônia Soares - Doutora em Ética pela Universidade Federal do Rio Grande do Norte (UFRN). Professora de Bioética e de Vigilância Sanitária do Departamento de Nutrição da UFRN. Nutricionista da Vigilância Sanitária de Natal. Natal/RN, Brasil.E-mail: soniafilos@yahoo.com 